\title{
JUDICIALIZAÇÃO DAS DEMANDAS DE VACINAÇÃO EM CRIANÇAS E ADOLESCENTES: A BUSCA PELA EFETIVAÇÃO DO MELHOR INTERESSE E PROTEÇÃO INTEGRAL
}

Letícia Prazeres Falcão ${ }^{1}$

\section{RESUMO}

A imunização de crianças e adolescentes transcende os aspectos sanitários. Notam-se ideologias, defesa pelo exercício parental livre, movimentos antivacinação e o entrave de políticas e recursos disponíveis. Pontos que envolvem essa discussão, revestem a busca do melhor interesse e proteção integral como princípios da condição de sujeitos de direitos do grupo. $O$ debate surge na análise do plano de fundo que confere à judicialização de imunização, reflexo de crises e que se não atentadas, correm o risco de retroalimentar o sistema e prejudicar a concretização desses direitos. A metodologia utilizada consiste na revisão de teses e artigos no viés indutivo.

Palavras-chave: Judicialização; Vacinação; Melhor Interesse; Proteção Integral; Crianças

\section{JUDICIALIZATION OF VACCINATION DEMANDS IN CHILDREN AND ADOLESCENTS: THE SEARCH FOR EFFECTIVENESS OF THE BEST INTEREST AND INTEGRAL PROTECTION}

\begin{abstract}
The immunization of children and adolescents transcends health aspects. There are ideologies, defense by free parental exercise, anti-vaccination movements and obstacle to available policies and resources. Points that involve discussion cover the search for the best interest and integral protection as principles of the condition subjects of group rights. The debate arises the analysis of the background that confers to the judicialization of immunization, reflecting crises and that, if not attempted, run the risk of feeding back the system and jeopardizing the realization of these rights. The methodology used consists of the review of theses and articles on inductive basis.
\end{abstract}

Keywords: Judicialization; Vaccination; Best Interest; Comprehensive Protection; Children

\section{INTRODUÇÃO}

O Poder Judiciário vem recebendo demandas inéditas que dizem respeito à searas antes não exploradas, sujeitos antes não (re) conhecidos e enfrentamentos que a priori, podem não dizer respeito às suas atribuições, mas que muito dizem sobre o sistema ao qual está vinculado e como sua postura pode influenciar direta e indiretamente na resolução dos mais

\footnotetext{
${ }^{1}$ Mestranda em Processo e Direito ao Desenvolvimento pela Unichristus (CE). Especialista em Direito do Consumidor e Direito da Família, Infância e Juventude. Mediadora e Conciliadora pelo Tribunal de Justiça do Maranhão
}

Revista de Direito de Família e Sucessão | e-ISSN: 2526-0227 | Encontro Virtual | v. 6 | n. 2 |

p. 74 - 95 | Jul/Dez. 2020. 
diversos conflitos. Por óbvio, apesar da construção desse papel ativista e politizador dos tribunais trazer a discussão de temas importantes, deve ser analisado com calma visto que as problemáticas podem ser mais profundas e as consequências podem reverberar em sujeitos já excluídos pelas conjunturas.

As demandas pela vacinação de crianças e adolescentes chegam aos tribunais demonstrando o embate entre uma suposta autonomia parental e a garantia de direitos fundamentais frente à interesses que vão desde o exercer dessa liberdade por pais e responsáveis até a promoção de direitos sociais por parte do Estado. A linha que separa tudo que abarca essa discussão é tênue visto que é no caso concreto que se pode levantar até onde vão os poderes-deveres familiares, o que seria ou não intervenções estatais dentro desse âmbito privado, qual o cenário das políticas públicas e campanhas de vacinação e como os princípios do melhor interesse e proteção integral devem, ou pelo menos, deveriam ser lidos à luz de diplomas normativos e construções socias. A problemática apresentada consiste então no averiguar de como a judicialização dessas demandas imunizantes representam não só esse novo atuar por parte do Poder Judiciário, como também em uma nova modalidade de acesso à Justiça de crianças e adolescentes na busca pela materialização de deus direitos.

De início, faz-se mister atentar para o debate dos movimentos antivacinação e como esse cenário se dá de modo a influenciar decisões parentais, estudos científicos, meios de comunicação e mídia, demandas de mercado e governamentais. Ressalta-se a relevância da justificativa do ato de vacinar e como este representa não só a proteção individual, mas também pode garantir a segurança sanitária e direito à saúde de toda uma coletividade. Posteriormente, se apresenta o alcançar do status de sujeito de direitos e como esse reconhecimento auxilia no entender das vulnerabilidades intrínsecas e extrínsecas de crianças e adolescentes, de modo a compreender que não há que se falar de condição especial de desenvolvimento sem o levar em conta o contexto ao qual se está falando.

Por último, falar-se-á da atividade de judicilização frente à politização dessas novas questões sociais e como a temática da vacinação tem sido vislumbrada dentro e fora das decisões judicias. Pensar no que abarcaria mandamentos de cumprimento no tocante à imunização de crianças e adolescentes, reflete não só a necessidade de atuação conjunta entre os poderes, mesmo estando estes em desconexão com as necessidades reais, como as 
implicações que as demandas vacinais trazem para a promoção de direitos fundamentais e os princípios do melhor interesse e proteção integral.

Quanto à metodologia, acredita-se que o procedimento funcionalista se faz cabível tendo em vista o pressuposto de que a sociedade é formada por partes inter-relacionadas, exercendo cada uma delas uma função essencial na vida em sociedade e no caso em comento, tratar de judicialização de demandas imunizatórias, é explorar os aspectos que contribuem para o chegar nesta etapa. O método científico utilizado será o indutivo haja vista a setorização dos componentes que envolvem o debate proposto até o chegar na problemática efetiva, e por fim se faz interessante a revisão de teses, artigos e matérias de revistas para compor a reflexão. (FINCATO, 2014).

\section{O CENÁRIO DA CULTURA ANTIVACINAÇÃO}

O advento da pandemia do COVID-19 parece ter trazido consigo não só a relevância da busca por medicamentos capazes de combater o vírus, como também o surgimento de uma vacina apta para a doença. Estar-se-á falando de uma corrida contra o tempo da comunidade cientifica na qual o caminho nem sempre é o mais fácil e célere, haja vista tratar-se da salvaguarda de vidas e estas necessitarem de um cuidado especial no tocante ao desenvolvimento, comercialização e distribuição dessas substâncias imunizantes.

Apesar de ser visível como as vacinas salvaram milhares de vidas ao longo da história, têm-se de um lado movimentos ativistas antivacinação que defendem a não utilização desse método por diversas razões, mesmo com esta posição é importante ressaltar que o que está em jogo vai além de convicções pró e contra mas sim, a efetivação de garantias fundamentais que desembocam na reflexão dos sujeitos mais afetados nessa aparente dicotomia: crianças e adolescentes.

O cenário negativista a respeito do uso das vacinas perpetua posições de cunho político, religioso, ideológico, espiritual, econômico e social. Mas foi com o advento do artigo escrito e publicado pelo médico Andrew Wakefield, no ano de 1998, que o movimento ganhou força. $\mathrm{O}$ estudo apontava que a vacina tríplice utilizada no público infantil no combate à rubéola, caxumba e sarampo poderia causar autismo como efeito colateral para além de inflamações no intestino. O fato de ter sido publicado na revista The Lancet foi outro fator que parece ter dado mais legitimidade para a investigação colocada, rapidamente famílias, 
alguns governos e representantes da sociedade começaram a defender a não aplicação em crianças e adolescentes (HUSSAIN A, et al., 2018)

A metodologia que fora escolhida pelo médico passou a ser questionada e rebatida por diversos pesquisadores, os resultados se mostravam duvidosos inclusive pela equipe de profissionais que participaram do estudo inicial. No ano de 2010, o Conselho Geral de Medicina do Reino Unido (GMC) declarou Wakefield como inapto para exercer a profissão, colocando-o ainda como alguém que teria atentado contra a saúde pública a divulgar um estudo antiético e enganoso. A revista precisou emitir uma retratação para com toda a comunidade declarando as supostas evidências como "totalmente falsas", a tentativa no caso foi de resgate da disseminação de uma informação que transcende os aspectos científicos e coloca em risco esferas individuais e de saúde pública (BELTRÃO R, et al.,2010).

A complexidade que envolve tais movimentos merece atenção visto que tomando por base o caso em questão, mesmo com a correção por parte da comunidade editorial, já se fazia perceptível a formação mais sólida de posições contrárias principalmente em países de origem do commom law. Nos Estados Unidos, esse negativismo nos últimos anos ganhou novos adeptos a partir de posições iniciais do presidente Donald Trump que parecia questionar a validade e eficácia da cobertura vacinal. Alguns estados americanos aceitam a recusa vacinal levando em consideração crenças religiosas e abstenções de cunho filosófico, determinam tais motivações como exclusões de ilicitude e acabam por isentar pais e responsáveis de qualquer sanção (VASCONCELLOS-SILVA; CASTIEL; GRIEP, 2015).

A hesitação vacinal $^{2}$ consegue estar presente em diversos contextos familiares e quebra determinados pré-conceitos de que a não aceitação ou reação duvidosa estaria em famílias com poucos recursos ou baixa escolaridade. Camadas médias e altas da sociedade brasileiras, por exemplo, também oscilam no reconhecer da relevância das políticas de imunização, a diversidade de posturas varia de acordo com o capital simbólico e que hoje parece poder tanto auxiliar na formação de senso crítico, como também corroborar para processos de alienação (BARBIERI; COUTO; AITH, 2017).

Para além de condutas do âmbito privado de famílias para com suas crianças e adolescentes, há também uma significativa ingerência de alguns setores empresariais,

\footnotetext{
${ }^{2}$ Por hesitação vacinal pode-se entender como o retardo ou renúncia total da aplicação de vacinas frente à disponibilidade de serviços e políticas. Alguns grupos como "pais de crianças e adolescentes, gestantes, idosos e profissionais da saúde que decidem não se vacinar" fazem parte de um nicho da sociedade que diverge muito sobre a aceitabilidade da imunização (SUCCI, 2018).
} 
farmacológicos, laboratoriais, políticos e de planos de saúde que podem financiar ou intermediar campanhas anti-vacina. Seja de forma direta ou indireta, certo é que o interesse e pensamento capitalista acaba por embasar tais movimentos e deturpam informações e dados para que o ato de vacinar ganhe a roupagem de periculosidade. Basta pensar que não havendo essa cobertura de imunização, e com a superveniência de doenças, cresce a demanda por procura de aparelhos médicos, profissionais de iniciativa privada, produção de medicamentos e toda uma mobilização do setor privado que olha as situações de enfermidade como oportunidades de ganho econômico.

A linha entre o exercício do poder familiar e autonomia de responsáveis frente à esta garantia de vacinação para crianças e adolescentes é muito tênue e pode ser detectada se forem levantadas as circunstâncias que embasam a sociedade hodierna. Com o aprimoramento e desenvolvimento dos meios de comunicação, a transmissão e captação de mensagens e dados ganhou velocidade e uma maior abertura no acesso, todavia nota-se o aumento na disseminação das chamadas Fake News que encorpam posicionamentos e interesses sociais, políticos ou econômicos desviados de comprovações cientificas. A cultura do cenário antivacinação, na sociedade pós-moderna ou pós-globalizada se utiliza desse desserviço para justificar a rejeição e acabam por influenciar novas e antigas condutas que colocam em risco a proteção e segurança pública sanitária (VASCONCELLOS-SILVA; CASTIEL; GRIEP, 2015).

A decisão individual pela não vacinação de crianças e adolescentes coloca em risco não só a saúde daqueles, como também transcende questões de foro íntimo e prejudica todo um interesse coletivo. Vacinar deveria ser tido para todos como um ato de responsabilidade cívica e que não deveria ser levado para o lado do ceticismo ou descrença na medicina preventiva. Doenças antes erradicadas em diversos países apresentaram novos surtos como no caso do sarampo e da caxumba no Brasil, há diante disto a comprovação de que não havendo a constância e seriedade para com as políticas de vacinação não há que se falar em terreno seguro quando o assunto é saúde pública (NASSARALLA A, et al., 2019).

\section{CRIANÇAS E ADOLESCENTES COMO SUJEITO DE DIREITOS NA CONTEMPORANEIDADE}


A proposta apresentada provoca não só o debate sobre os aspectos judiciais e sociais que envolvem os movimentos antivacina, como também remete a atenção para o grupo mais afetado pela recusa ou omissão diante desse contexto. Considerar crianças e adolescente como sujeitos de direitos perpassa sim por uma evolução histórica do próprio conceito de infância ${ }^{3}$, como também reconhece que a condição especial de desenvolvimento, e o que é relevante para sua promoção, deve levar em conta aspectos internos e externos desses indivíduos. Estarse-á tratando de vulnerabilidades de cunho intrínseco e extrínseco que os transporta da condição de anulabilidade e objetificação para a de personagens ativos e legítimos de uma proteção especial.

O status de sujeitos de direito aborda a perspectiva intrínseca quando se considera não só as lutas advindas pelo reconhecimento dos princípios humanistas e anti-minoristas como também o caráter etário. Levar em conta este ponto significa que esse público se encontra em um processo de formação física, psicológica e emocional que necessita de uma atenção diferenciada, nesse período as vulnerabilidades dizem respeito à própria formação e desenvolvimento desses sujeitos diante da comunidade. É colocá-los sob o foco da visibilidade e atentar para as condições especiais de tratamento, é encará-los sim como detentores de autonomia, como legítimos de uma responsabilidade tríade da família, Estado e sociedade, e prioridade em termos de políticas públicas e ações afirmativas para auxiliar nesse progresso de maturidade, por exemplo (DOS SANTOS; VERONESE, 2018).

A observação que veste a concepção intrínseca gira em torno do próprio advento de leituras e reflexões neoconstitucionalistas que abandonam a perspectiva jurídica exclusivamente posta e passam a admitir a valorização axiológica de princípios. Poderia ser levantado ainda uma tentativa de reaproximação entre Direito, sociedade e Estado que por muito tempo configuravam uma disposição dissociada e desproporcional, o olhar mais humano e sensível para com crianças e adolescentes ganha o empoderar da dignidade da

\footnotetext{
${ }^{3}$ A história da infância no Brasil perpassa por alguns estágios e sofre influências de legislações e modos de vida estrangeiras. Têm-se fases de indiferença absoluta e inexistência de normas tutelares de crianças e adolescentes com presença de um tratamento por vezes semelhante a de um adulto; observa-se também a fase da imputação criminal presente principalmente no Código de Menores, compilado legislativo que parece inaugurar o anseio pela proteção desses jovens mas em verdade reforça condutas discriminatórias e de exclusão; fase tutelar que coloca no mundo adulto a promoção nessa reinserção sociofamiliar com posturas assistencialistas e que dizem respeito em caráter reflexo aos interesses dos adultos e não do público infanto-juvenil; e finalmente a fase de proteção integral com o identificar de direitos e garantias e reconhecimento da situação de indivíduos em desenvolvimento (WAQUIM; COELHO; DE MORAES GODOY, 2018)
} 
pessoa humana e a evolução das garantias diante das dimensões de direitos fundamentais (LIMA;VERONESE, 2012).

Diante deste cenário parecem surgir novos direitos para "novos" sujeitos, entretanto é sabido que esse ineditismo não é tão verídico assim. Trata-se em verdade do reconhecimento de um grupo que há muito tempo existe mas que apenas recentemente conseguiu ser foco de atenção e detentor de uma tutela protetiva em detrimento de aspectos internos e externos. Abordar avanços como princípios da não discriminação, primazia absoluta, participação popular, proteção integral e politicas públicas sociais básicas, sem considerar quem são e em que circunstâncias estão esses indivíduos, é esvaziar toda uma construção.

Alguns diplomas normativos como a Declaração Universal dos Direitos Humanos de 1948, a Declaração Universal dos Direitos da Criança em 1959, Convenção sobre os Direitos da Criança de 1989, a Constituição Federal de 1988 e o Estatuto da Criança e Adolescente, lei 8.069/90, abrem espaço para as conquistas no campo dos direitos, estabelecendo a primazia de determinadas garantias voltadas à uma proteção infanto-juvenil que abarque o crescimento em sociedade (COSTA; DE ANDRADE; JUCÁ, 2016). Começa a ser montada uma espécie de rede de apoio e suporte na elaboração e concretização desses progressos, há o reforço dessa atenção por meio do papel das escolas e conselhos tutelares, o estabelecer de uma prioridade diante de políticas e instituições e a tentativa de diálogo entre as esferas públicas e privadas.

O próprio Direito de Família, passa a entender o Direito da Criança e Adolescente enquanto ramo autônomo, que possui relação com a perspectiva da estrutura familiar, mas em razão das suas especificidades necessita de um ambiente para seu estudo e promoção (DE BARROS, 2001). Não se faz razoável atribuir a posição de sujeito de necessidades para a posição de sujeito de direitos sem levar em conta as características, urgências e particularidades que lhes são próprias, possibilitar um ramo jurídico direcionado é fazer com que o Direito ${ }^{4}$ possa estar cada vez mais próximo do local que ao mesmo tempo que é campo de atuação, lhe é também berço de demandas.

A perspectiva humanista dessa proteção que nasce com a abordagem intrínseca desses sujeitos leva em consideração a própria essência da dignidade da pessoa humana. Falar de condição especial de desenvolvimento é respeitar dignidades peculiares de acordo com a fase de crescimento, e que por mais que se avance no sentido de produção legislativa, em nada

\footnotetext{
4‘"Para que o Direito possa retomar suas funções em plenitude é preciso recompô-lo, deixar que absorva e seja absorvido por um novo paradigma. [...] o Direito em trânsito é um movimento histórico, que lhe imprime uma natureza metatemporal, sinalizando mudança, transcendência e autorreflexão" (GERVASONI, 2017)
} 
adianta se esses direitos não estão interligados à factibilidade dessas garantias humanas e fundamentais (DOS SANTOS; VERONESE, 2018).

Outro fator que pode ter contribuído para o alcance desse novos status, seria o próprio inserir da visão afetiva para com a definição do conceito de família. Esta já não se resume no tocante à hierarquia ou no caráter sanguíneo, mas evolui e entende como um agrupamento, ou não, de pessoas que se unem em virtude do afeto e do sentimento eudemonista. Este novo olhar tem relação com a faceta humanista da proteção integral para com crianças e adolescentes, e com a própria questão da dignidade da pessoa humana. A maneira como crianças e adolescentes passam a ser percebidos na contemporaneidade possui relação com esse novo Direito de Família mais afetuoso, mais qualitativo, e mais próximo do real (DIAS; DE SOUZA, 2001).

A faceta extrínseca dessas vulnerabilidades ultrapassa o aspecto formal e estático e chega no contexto em que essas crianças e jovens estão inseridos. O fluxo socioeconômico que os rodeia torna-os frágeis não só pela, por vezes, não concretização dessas garantias, como também pela inexistência de condições materiais e capacitivas para essa operacionalização. Em muito se avançou na redação de legislações mas pouco se consegue atribuir uma efetividade na realização das mesmas. Garantias educacionais, sanitárias, de saúde, de lazer, de exercício da cidadania, erradicação de desigualdades, não discriminação e a proteção em uma sociedade livre e justa, parecem ser escopos próximos e ao mesmo tempo distantes de quem mais necessita (DOS SANTOS; VERONESE, 2018).

Ora, refletir sobre a vulnerabilidade socioeconômica é admitir que a percepção humanista dessas garantias, e no caso a proteção que é devida a crianças e adolescentes, em pouco adianta se não estiver em consonância com a materialidade imprescindível no campo prático. Em tanto se diz pelo transpor da ideia de Direito e norma que, no entanto, parece existir uma estagnação nesse exato sentido quando não se vislumbra por parte de instituições, agentes e sistemas responsáveis, o resguardo e a execução dessas conquistas. O garantir deve estar alinhado com as possibilidades de alcance desses princípios, deve levar em conta as realidades aos quais esses grupos estão inseridos, seus graus de desigualdade, pobreza, vulnerabilidades espaciais, geográficas, particularidades culturais, sociais e econômicos (DOS SANTOS; VERONESE, 2018).

O alcance da fase da proteção integral, e respectivamente, de sujeito de direitos, precisa ser visto à luz de uma leitura bidimensional da justiça social. É sim iniciar pela 
redistribuição e atenção para os seguimentos da "pobreza, exploração, desigualdade os diferenciais de classe", da mesma forma que é mister entender que esse (re)conhecer deve estar próximo no sentido da representatividade, luta contra desrespeito, subordinações estatais, participação na tomada de decisão, "imperialismos culturais" e valoração das identidades (FRASER, 2002).

Ainda neste tocante, as vulnerabilidades socioeconômicas não residem exclusivamente em famílias que carecem de melhores condições financeiras, errôneo pensar que crianças e adolescentes de outros meios não sofrem determinadas violências. As fragilidades também estão presentes quando se fala em transtornos alimentares, consumismo pela mídia e saúde mental, condições socioeconômicas mais "vantajosas" não são impedimentos para que haja o interferir e desrespeito da esfera de direitos infanto-juvenis (OLMOS, 2011). Em verdade, têm-se um sistema que a depender da esfera de atuação, ocorrerá a influência direta ou indiretamente nesse processo de luta dos direitos, reafirmação de particularidades, (re) distribuição de recursos e (re) conhecimento de identidades.

É preciso superar a antiga concepção de que o desrespeito e discriminação com o grupo infanto-juvenil acontece apenas nas periferias e nos países abaixo da Linha do Equador. Discursos humanistas e ocidentais por vezes, podem ser utilizados como forma de dominação e esta acontece de forma incisiva ou ainda de maneira sutil, os processos de controle e poder ganham uma roupagem pós-colonialista mas que perpetuam o apropriar de arguições, a elevação supostamente legítima de princípios estrangeiros e o distanciamento entre o dever e o ser no tocante às garantias fundamentais (FLORES, 2006).

A posição de sujeito de direitos é um processo, e assim como o desenvolvimento de crianças e adolescentes, algo constante e que necessita de atenção. Infelizmente algumas conquistas nas áreas políticas, jurídicas e econômicas não representam avanços sociais, culturais e de reconhecimento de identidade. Ser sujeito de direito na contemporaneidade é lutar contra sistemas hegemônicos antigos e novos, é entender que as necessidades não são universais e muito menos que esses indivíduos podem constituir objetos de entraves de interesses alheios quando são na realidade os verdadeiros protagonistas deste roteiro.

\section{ASPECTOS DA JUDICIALIZAÇÃO IMUNIZATÓRIA E A PROTEÇÃO DOS DIREITOS INFANTO-JUVENIS}


A procura pelo Poder Judiciário no tocante à busca pelos direitos de crianças e adolescentes e a matéria da vacinação, é um fenômeno revestido de causas internas e externas ao âmbito do Direito. Se de um lado, têm-se um aparente choque de interesses envolvendo grupos familiares, poderes públicos e a proteção e melhor interesse, de outro observa-se esse movimentar até os tribunais como uma saída para esses conflitos na medida em que, aparentemente caberia àquele a "esperança" pela realização da justiça.

Durante esse processo de reconhecimento, reafirmação e concretização dessas garantias têm-se em verdade um confronto com as próprias regras dos sistemas hegemônicos que ditam os fluxos de cada paradigma e colocam grupos de indivíduos em situação de vulnerabilidade. Esses conjuntos transcendem os sentidos quantitativos de minorias e podem ser tidos enquanto vulneráveis em razão da ausência de poder, ausência do exercício mais participativo e relevante diante da prática cidadã, como também acabam se tornando alvos de sofrimento, desrespeito e discriminação (COSTA; DE ANDRADE; JUCÁ, 2016).

Diante desse debate, é notório que as decisões judiciais que envolvem determinações para a procedência da imunização de crianças e adolescentes, são revestidas de uma dualidade principiológica que a depender de quem a propaga, podem estar totalmente dissociadas com as primordialidades inerentes à esta fase de desenvolvimento. Existe uma colocação absoluta de interesses e um dito correto exercício parental frente à uma distorção do que seria de fato melhor interesse e o que conferiria a real proteção. Nota-se então uma tendência no atuar judicial para algumas intervenções não só no equilíbrio dessas posições, mas sim no elevar do acesso à justiça de grupos historicamente vulneráveis e carentes de olhares sensíveis.

Em apelação cível julgada pelo Tribunal de Justiça do Estado de São Paulo, na data de onze de julho de 2019, na comarca de Paulínia, fora levado ao debate para o colegiado a demanda na qual pais de uma criança de três anos sustentavam a sua liberalidade no tocante à vacinação da mesma. A roupagem que envolvia a escolha parental era baseada na concepção individual da pouca intervenção, no fato de que o filho aparentava estar saudável e tal ação se fazia desnecessária, do pouco contato social escolar, o que contribuía supostamente para essa segurança imunizatória, para além de levantaram a existência de substância nas vacinas que estaria ligada ao desenvolvimento cancerígeno e autista (ROVER, 2019).

A decisão em comento que determinou pela vacinação, merece destaque para alguns pontos no que diz respeito em como a faceta principiológica fora trabalhada, a atuação de 
quem levou a discussão aos tribunais e o papel do Poder Judiciário nesse sentido. Para isto, têm-se como plano de fundo o voto do relator:

PODER FAMILIAR - VACINAÇÃO OBRIGATÓRIA - AÇÃO PROPOSTA PELO MINISTÉRIO PÚBLICO PARA IMPOR AOS PAIS A OBRIGAÇÃO DE PROCEDER À VACINAÇÃO OBRIGATÓRIA DE FILHO MENOR SENTENÇA QUE NÃO RECONHECE A OBRIGAÇÃO, SOB O FUNDAMENTO DA EXISTÊNCIA DE RISCO CONCRETO DA VACINAÇ̃̃O, DA LIBERDADE DE CONSCIÊNCIA E DE ORGANIZAÇÃO FAMILIAR, BEM COMO DA INEXISTÊNCIA DE OMISSÃO OBRIGAÇÃ̃O DOS PAIS DE PROCEDER À VACINAÇÃO DE FILHOS MENORES QUE DECORRE DE NORMA DE ORDEM PÚBLICA INEXISTÊNCIA CONCRETA DE PROVAS A INDICAR O RISCO EM SE PROCEDER À VACINAÇÃO - ORGANISMOS INTERNACIONAIS QUE RECONHECEM A INEXISTÊNCIA DE RISCO GRAVE E DE BENEFÍCIOS COM A VACINAÇÃO - NORMATIZAÇÃO A INDICAR QUE A VACINAÇ̃̃O OBRIGATÓRIA INTEGRA CONJUNTO DE REGRAS DE ORDEM PÚBLICA, TUTELA NÃO SÓ A SAÚDE DA CRIANÇA, MAS TAMBÉM DA COLETIVIDADE - NEGATIVA À VACINAÇÃ̃O QUE CONSTITUI INFRAÇÃO SANITÁRIA - CONFLITO DE DIREITOS FUNDAMENTAIS QUE DEVE SER DECIDIDO PELA PREVALÊNCIA DOS INTERESSES DA CRIANÇA E DE SUA SAÚDE, BEM COMO DA COLETIVIDADE - LIBERDADE FILOSÓFICA E RELIGIOSA QUE NÃO TEM CARÁTER ABSOLUTO QUANDO ATINGEM TERCEIROS OBRIGAÇÃO DOS GENITORES DE REGULARIZAR A VACINAÇÃO POSSIBILIDADE DE SUSPENSÃO TEMPORÁRIA DO PODER FAMILIAR PARA A REgUlaRizaÇÃO DA VACINAÇÃO DA CRIANÇA PELO CONSELHO TUTELAR-RECURSO PROVIDO PARA JULGAR PROCEDENTE A AÇÃO (TJSP - Câmara Especial - Apelação no 100328483.2017.8.26.0428 - Relator: Fernando Torres Garcia (Presidente da Seção de Direito Criminal) - 11 de julho de 2019)

O plano de fundo principiológico recentemente alçou patamares mais altos e passou a ser devidamente encorpado nas leituras, reflexões e decisões judiciais. Apesar de ser um aspecto mais abstrato e axiológico, tais mandamentos de otimização em muito colaboram para uma aproximação da teoria e do campo prático (ALEXY, 2012). Em que pese o avanço, nem sempre ocorrera a atenção devida, a discrepância entre as perspectivas do ser e do dever principiológico conviveram e ainda convivem com as dissociações do Direito, Estado e sociedade.

4.1 A dissociação do melhor interesse e proteção integral

O melhor interesse e proteção integral são princípios afirmados e resguardados pela Constituição Federal de 1988, possuem um viés humanista, a conexão com a essência da 
dignidade da pessoa humana, assim como estão conectados com outras leituras sistemáticas de todo um ordenamento (DOS SANTOS; VERONESE, 2018). Desse panorama axiológico, é possível encontrar outros subprincípios que se legitimam nesse sentido e consubstanciam produções legislativas, políticas públicas, a responsabilidade tríade de sociedade, família e Estado, e o reconhecimento do status de sujeito de direito e detentores de uma condição especial de desenvolvimento, por exemplo.

A aplicação vacinal para este grupo específico, passou a ter obrigatoriedade pela Lei $\mathrm{n}^{\circ}$ 6.259/75 e ganhou o reforço do Estatuto da Criança e Adolescente, em seu artigo 14, parágrafo $1^{\circ}$, tais evoluções legislativas obtiveram como escopo o dever de cuidado, para além do estabelecer de eventuais punições para os responsáveis em caso de descumprimento (PAES, 2018). Tais colocações são aceitáveis do ponto de vista que o quê quer ser protegido e promovido é o crescimento saudável e seguro do grupo em razão do processo de crescimento e desenvolvimento, vislumbra-se uma série de peculiaridades físicas, biológicas, psicológicas, espaciais e sociais que os torna vulneráveis em diversos sentidos e por isso, merecem uma dedicação e zelo diferenciados.

Tomando como base o que fora levantado, a decisão analisada e o voto apresentados demonstram que levantar um suposto melhor interesse e uma teórica proteção oriundos da liberdade do exercício parental, quando estes não estão conexos com a realidade e factíveis necessidades da criança, é atentar contra valores constitucionalmente previstos. Esse poderdever parental não pode ser colocado e alçado de forma totalitária e absoluta de modo a passar de maneira desmedida por aspectos sensíveis que vão além de posições e interesses particulares, tratando em verdade de questões de interesse público (DE CAMPOS; RODRIGUES; PINTO, 2019).

A discussão que envolve as políticas de vacinação e a proteção de crianças e adolescentes é algo que transcende convicções pessoais e desemboca em colocações de bemestar e segurança sanitária de toda uma população. Tais grupos para além de se tornarem um público que venha a sofrer com maiores consequências, podem ainda se tornar vetor de transmissão de doenças antes erradicadas mas que por conta desses movimentos antivacina, voltaram a circundar países e comunidades (ROVER, 2019). Essa falha no sistema de imunização também reflete no colapso de sistemas de saúde e aumento da taxa de ocupação de leitos, por exemplo. No momento em que um dito cabido exercício parental se põe diante dessas questões, tal direito de liberdade filosófica ou religiosa, como expõe o voto do relator, 
vai de encontro com o atingir de esferas terceiras e deve ceder lugar à preponderância da manutenção e proteção da vida e saúde pública.

Não se pode dizer que o quê deva ser considerado melhor ou consonante à proteção devida, seja necessariamente o que esteja relacionado à vontade parental. Por óbvio não se está defendendo toda e qualquer intervenção estatal dentro do âmbito privado das famílias, mas no momento em que as escolhas individuais não respeitam as garantias infanto-juvenis, se faz mister tal ingerência. Os valores alçados devem estar também em sintonia com os do Estatuto da Criança e Adolescente, da Carta Magna, dispositivos infraconstitucionais e internacionais, atenta-se não para o espulgar da autonomia de pais e responsáveis, mas a cautela com um exercício desmedido e desrespeitoso.

Falar em proteção integral e melhor interesse não pode estar associado a preceitos deturpados, não podem fundamentar ações evasivas ou omissas ou ainda utilizados para excluir e menosprezar aqueles que mais carecem. Se faz de caráter sério e emergencial proteger as gerações presentes e viabilização das futuras, não se pode tornar irrelevante as construções axiológicas em nome de uma liberdade absoluta. Perigoso, em verdade, se faz em não detectar a existência de limites na aplicação da autonomia parental, ao tempo todo vislumbra-se um interseccionar de vulnerabilidades que devem auxiliar na transformação da realidade fática e não um destruir do conhecimento e valoração principiológica com impactos diretos no campo social (FRASER, 2002).

\subsection{Judicialização de demandas vacinais e acesso à Justiça}

A questão da judicialização é um fenômeno que pode ser explicado a partir da suas estruturas-base, quais sejam: Estado e sociedade. O protagonismo dos tribunais e a transformação estatal acontecem em um momento no qual se observa o desmantelar do Estado intervencionista e provedor, a precarização de direitos, a submissão às regras de mercado, existência de expectativas frustradas, crises de desconfiança em instâncias políticas clássicas e a tentativa de solucionar as demandas individuais e proteção de garantias fundamentais. A sociedade parece estar solitária diante da ausência de um "fio condutor", órfã no tocante à inexistência de um centro protetor e promovedor, vive-se uma crise democrática na qual as debilidades das promessas neoliberais não cumpridas, aumento das desigualdades e o fomento 
à cultura do indiferente são fatores que contribuem para esse novo atuar judicial (MAUS, 2000).

Esse movimento de descompasso entre o campo social e o agir estatal gera desconexões que prejudicam políticas públicas, materialização de direitos, o não exercício democrático e a hipertrofia de algumas instâncias. Demandas que originalmente eram de outras esferas, procuram na atuação dos magistrados e demais atores do Poder Judiciário a ampliação desse acesso à efetivação de garantias que parece ter sido deixado de lado.

A judicialização envolvendo a temática social escancara o retroceder estatal no enfrentamento dos velhos e novos anseios da sociedade contemporânea ao mesmo tempo que abre espaço para o que chamam desse atuar mais político por parte dos tribunais. Entretanto, apesar de contribuir muito para uma melhoria nas resoluções dos conflitos e na materialização de direitos fundamentais e determinadas ações públicas, essa atuação extraordinária, se desmedida, pode interferir no aumento de desigualdades sociais já existentes e que podem ser intensificados.

Encarar a judicialização como a salvaguarda da sociedade pós-moderna acarreta também na possibilidade de que esses instrumentos possam vir a sancionar grupos vulneráveis que já sofrem com uma exclusão e negligência históricas. Mulheres, negros, idosos, crianças e adolescentes, população indígena e grupos LGBT, por exemplo, ao serem alvo de atuações judiciais mais ativistas podem sofrer por via reflexa com o agravamento dessas esquinas de vulnerabilidade se as decisões e o atuar judicial forem muito específicos, alheios ao contexto ao qual estão inseridos e se não houver demais ferramentas e recursos no acolhimento desses sujeitos para a satisfação e gerenciamento das demandas sociais (MATOS, 2013).

As demandas pela imunização chegam aos tribunais porque estar-se-á diante de crises na sociedade que reverberam na esfera de crianças e adolescentes, crises que podem estar ligadas ao absolutismo da autonomia parental ou pelo descaso de autoridades públicas para com o cuidado e acompanhamento desses grupos. Elas alcançam o Poder Judiciário porque os mais próximos, e aqui não se considera o Judiciário como o mais distante dos poderes, parecem estar muito longínquos na leitura e compreensão dessas causas. Se princípios são distorcidos em prol de um suposto melhor interesse e proteção integral, a faceta da liberdade filosófica ou religiosa parece ter uma prioridade considerável, órgãos municipais e estaduais se eximindo de algumas ações e parte do sistema parece convergir para o negacionismo. 
Apesar de louvável, e como bem explicitado acima, em pouco adianta ter uma via de escape se a mesma contribuir para os estados de ameaça e lesão à determinadas garantias fundamentais. Será que é questionável qual o perfil das famílias que estabelecem esse embate entre direitos e obrigações? Após a determinação judicial, se a procura da vacina for em rede pública e esta não se encontrar disponível, a satisfação estaria prejudicada? Haja vista, em um determinado caso a família não possuir condições de ir para a rede particular, se correria o risco de perder a guarda da criança? Estes casos isolados auxiliariam em um crescimento quantitativo e qualitativo das campanhas de vacinação? Seria mais viável que varas judicias que recebessem as demandas de vacinação, dispusessem de equipes multidisciplinares para um atendimento prévio ou concomitante o processo? São questionamentos que nascem de casos particulares mas possuem seu aspecto originário em situações de base, base da sociedade, problemas estruturais e desigualdades sociais.

A problemática entre a promoção do direito à saúde, que está correlacionada ao da vida e dignidade da pessoa humana, e o aumento de demandas judiciais também representa referências da análise econômica do Direito. Isto ocorre pois tendo em vista a faceta promovedora e garantidora do Estado Social, a partir da Constituição Federal de 1988 se estabeleceu um rol de direitos sociais e pouco se atentou para a viabilização dos mesmos, em muito se avançou na leitura e detecção de algumas necessidades e pouco se reportou para a maneira de concretizá-las, para os recursos utilizados e para os agentes responsabilizados. É difícil pensar na promoção de políticas públicas quando os recursos, alegados pelo poder público, são insuficientes para arcar com todas as demandas e quando os impactos financeiros sustentados são mostrados como de grandes proporções (POTTUMATTI; MEIRELLES, 2014)

Se de um lado o Estado tende a economizar e escolher a aplicabilidade dos recursos, têm-se do outro lado um aumento consequente de outros problemas sociais, o incremento de ações judicias e a aplicação das decisões em casos específicos. A postura de um magistrado para a determinação de concessão de vaga em leito de UTI, por exemplo, implica na não colocação de outra pessoa, a vacinação de uma criança implicaria na desigualdade em comparação com outras, e a cada questionamento as escolhas ficam mais difíceis de serem sopesadas, mesmo havendo metodologias e princípios que auxiliem, as tragic choices configuram uma nova característica em tempos de judicialização de crises sociais e de saúde (GLOBEKNER, 2017). 
Trazendo para a decisão judicial mencionada em termos de determinação imunizatória, vale a pensa questionar se as determinações incluiriam também a aplicação somente da vacina, a repetição de doses, tratamentos medicamentais paralelos que aumentariam a eficácia da vacinação ou se incluiria o auxílio médico em eventual efeito adverso já conhecido pela comunidade científica. Nota-se judicializar demandas imunizatórias abarcam outras discussões que não se resumem exclusivamente à aplicação da vacina, o sistema ao qual se inclui as políticas públicas, direitos sociais e a alocação de recursos é muito mais complexo, as searas estão interligadas e o agir isolado em uma pode não ter sucesso se não estiver em sintonia com os demais.

O contexto do caso trazido também demonstra como conceitos culturais, preferências ideológicas e a não correta forma de veiculação e publicidade de campanhas podem influenciar na decisão pela não aplicação de vacinas e posterior pleito judicial. A campanha de vacinação contra o HPV em meninas de 11 a 13 anos esbarrou nesses óbices no instante em que se percebeu a existência de informações e peças publicitárias duvidosas que dariam margem a diversas interpretações, representando assim combustíveis para esta falha na promoção da saúde dessas jovens (DE QUEVEDO, J. et al., 2016). O resultado acaba sendo o não atingir das metas públicas de imunização, a construção social e ideológica da representatividade daquele agente imunizador, o aumento de casos de infecções pelo vírus do HPV, aumento nos questionamentos para com as instituições públicas de governo e eventual busca no judiciário para reparação.

\footnotetext{
Nessa comunicação institucional inicial não se explicitou uma relação direta entre a vacina e a prevenção da oncogênese. Na peça em que aparecem mãe e filha não se estabeleceu uma conexão direta entre a importância da vacinação na adolescência e o objetivo de se tentar evitar a doença na fase adulta. [...] As reações de um público crítico à imunização e a polêmica em torno do tema da sexualidade colocaram em evidência que a concepção de usuários e o enquadramento do problema da prevenção do câncer latentes no desenho da vacina e divulgados pela campanha oficial entraram em choque com as perspectivas e valores dos potenciais usuários (DE QUEVEDO, J. et al., 2016, p. 9-10).
}

O acesso à Justiça que reveste a discussão levantada engloba para além da judicialização de demandas imunizatórias, o contexto no qual vivem essas crianças e adolescentes, visto que não há que se falar em decisões mandamentais sem a viabilidade fática de cumprimento. Se faz mister também levar em consideração as concepções para além das jurídicas que impedem ou reforçam essa política sanitária, qual parte do todo que as decisões conseguem abarcar, como podem reforçar ou criar mais disparidades e de que maneira seria a 
atuação executiva e legislativa diante da escassez de recursos. Talvez se faça preciso analisar esse acesso não exclusivamente como a porta de entrada, mas o que se encontra antes disso, de que maneira esse acesso é posto, acesso para quem e para o quê até se chegar na questão da Justiça em si.

A temática apresenta ainda outra gama de atores que representam esse buscar das garantias de crianças e adolescentes diante da importância da vacinação. O caso na cidade de Paulínia, demonstra o relevante papel do Conselho Tutelar na comunicação para com o Ministério Público, o impacto positivo que essa rede em torno de grupos vulneráveis pode ter e como deve ocorrer o diálogo e atuação da responsabilidade tríade (ROVER, 2019). No caso do Ministério Público, vale a menção da Ação Civil Pública ajuizada no ano de 2010 contra o Estado do Paraná e a União (Ministério de Saúde), no que diz respeito aos critérios adotados para a campanha e calendário de vacinação contra o vírus da gripe influenza A - H1N1:

\footnotetext{
Em síntese, para consubstanciar o pedido de ampliação do fornecimento da vacina contra o vírus da gripe "tipo A" para todos os paranaenses, sustentou o Parquet: a) que a medida da União seria discriminatória, na medida em que garantiu a imunização gratuita somente a parte da população brasileira; b) que às pessoas pertencentes ao grupo de não risco estaria a União negando"não apenas o direito à saúde, como também, em última análise, o próprio direito à vida"; e c)que o Estado do Paraná teria sido o mais afetado pela gripe no ano imediatamente anterior, sobretudo se comparado aos Estados da região nordeste do país, razão pela qual deveriam ser consideradas as peculiaridades climáticas e de incidência recente da doença na definição dos grupos de risco - justificando a imunização de toda a população paranaense - o que não teria sido observado pela União (DE ANDRADE, 2010, p. 6).
}

Dos núcleos mais próximos aos mais remotos, devem ser percebidos atores que tomam para si o compromisso na proteção desses direitos fundamentais e viabilizam a essência do acesso à Justiça para crianças e adolescentes. Escolas, creches e associações são outros núcleos que podem perceber a afronta garantista e reportar aos órgãos e instituições para o iniciar das reparações judiciais. Ao se perceber eventual omissão ou negligência por parte da esfera familiar, cabe aos demais legitimados a postura ativa necessária, e aqui não se fala do tomar para si de maneira absoluta e autoritária suposta posição, mas sim de reconhecer a condição especial de desenvolvimento assim como a de sujeito de direitos desses jovens e diante disto auxiliar na correta e sensata condução que viria a ser o melhor interesse e proteção integral. 
$\mathrm{O}$ ato de judicializar, de fato, pode ser encarado enquanto uma modalidade de acesso à Justiça uma vez que demais agentes falham nesse atuar, políticas públicas não são promovidas de maneira democrática e direitos individuais e sociais são deixados de lado em prol de interesses econômicos, ideológicos ou governamentais. Todavia, é possível perceber que o judicializar em demasia e feito de maneira rasa reporta em um sistema de crises que pode ser retroalimentado e aprofundar as diferenças já tão existentes.

A judicialização não deve ser a resposta para tudo, o direito à saúde e à vida de crianças e adolescentes também não pode ficar à mercê das mãos de magistrados que nem sempre conhecem ou se colocam a conhecer as realidades. O Direito é uma ciência social e tendo em vista a complexidade das demandas contemporâneas, deve dar às mesmas respostas cabíveis na medida de suas complexidades, não se pode tratar como simples questões que retratam disparidade históricas e sócio-políticas. Deve estar aberto ao auxilio e contribuição das demais áreas, dos demais sujeitos, dos diversos roteiros, afinal de contas as portas para a materialização de um melhor interesse e proteção integral de crianças e adolescentes são diversas, contudo, o acesso que conta é o perpassar e o sair por àquelas com a satisfação e possibilidade de concretização das garantias tão almejadas.

\section{CONCLUSÃO}

A temática proposta convida para uma reflexão transdisciplinar e multifatorial quando coloca a demanda judicial por vacinação de crianças e adolescentes como um quebra-cabeça com diversas partes. Cada uma possui um papel importante no montar desse cenário visto que traz consigo determinada particularidade que influencia diretamente ou indiretamente na montagem da imagem central. Provocar essa discussão é não só importante do ponto de vista jurídico, como também contribui para um pensar mais crítico e próximo dos verdadeiros atores da dinâmica social nos âmbitos científicos, econômicos, farmacológicos e políticos.

Os movimentos e a cultura da antivacinação são revestidos de propósitos que distorcem dados e informações, se utilizam da praticidade e da característica transfronteiriça da globalização e colocam sujeitos vulneráveis em situações de um intensificar dessa vulnerabilidade, contribuem para o expor a risco a saúde desse público e de maneira reflexa ameaçam a segurança e saúde pública. Por mais que em determinadas doenças infectocontagiosas se vise a imunização de um grupo de risco, a ideia é proteger aqueles que 
por alguma condição especial estariam mais propícios a consequências perigosas, do mesmo modo que se planeja a contenção de transmissões para o pensar concomitante de como receber e tratar outras categorias de pacientes, por exemplo.

A construção da condição de sujeito de direitos de crianças e adolescentes é um percorrer de fases que vão desde a indiferença até o considerar tais indivíduos como legítimos de uma proteção especial, de uma promoção de possibilidades, oportunidades plenas e adequadas para seu desenvolvimento particular. É reconhecê-los como dignos da busca do melhor interesse haja vista não só as indispensabilidades atuais, como também por entender que os mesmos são os futuros agentes de mudança social. Todavia, não há que se falar em modificação de status quo e transformações significativas sem o empoderar e a criação de desenvolvimento de liberdades e capacidades.

Judicializar algumas demandas, aspectos de crises e dilemas sociais parece ser uma das saídas para uma desestruturação estatal maior que desemboca no fragilizar de instituições, exercícios atípicos e complexidade de dualidades entre a promoção de direitos e a dita reserva do possível. No caso da vacinação de crianças e adolescentes, a resolução dos conflitos não pode ser tida de maneira simplória e deve, na medida do possível, levar em consideração alguns aspectos da viabilidade dessa ação, o contexto que reveste a vida desses jovens e a atuação de outros sujeitos que contribuem para a proteção e melhor interesse. Politizar a vacinação diante dos tribunais é sim tentar viabilizar essa condição de desenvolvimento mas se não conexa com demais fatores que encorpam a discussão, podem ser esvaziadas e reduzidas a casos particulares de acesso à Justiça.

\section{REFERÊNCIAS}

ALEXY, Robert. Teoria dos Direitos Fundamentais. $2^{a}$ ed. São Paulo. Editora Malheiros, 2012.

BARBIERI, Carolina Luisa Alves; COUTO, Márcia Thereza; AITH, Fernando Mussa Abujamra. A (não) vacinação infantil entre a cultura e a lei: os significados atribuídos por casais de camadas médias de São Paulo, Brasil. Cadernos de Saúde Pública, v. 33, p. e00173315, $2017 . \quad$ Disponivel em: https://www.scielosp.org/article/csp/2017.v33n2/e00173315/pt/. Acesso em 08 de junho de 2020

BELTRÃO, Renata Paula Lima et al. Perigo do movimento antivacina: análise epidemioliterária do movimento antivacinação no Brasil. Revista Eletrônica Acervo Saúde, v. 12, n. 
6, p. e3088-e3088, 2020. Disponivel em: https://www.acervomais.com.br/index.php/saude/article/view/3088. Acesso em 08 de junho de 2020

COSTA, Andréia da Silva; DE ANDRADE, Denise Almeida; JUCÁ, Roberta Laena Costa. A concretização do princípio constitucional da solidariedade no âmbito da violência sexual contra crianças e adolescentes. In: CASTILHO, Natalia Martinuzzi; GONÇALVES, Camila Figueiredo Oliveira; SALES, Gabrielle Bezerra. A Concretização dos Direitos Fundamentais na Contemporaneidade. Boulesis Editora, 2016.

DE ANDRADE, Ricardo Barretto. Da falta de efetividade à intervenção judicial excessiva. Revista Brasileira de Direitos Fundamentais \& Justiça, v. 4, n. 12, p. 78-91, 2010. Disponivel em: http://dfj.emnuvens.com.br/dfj/article/view/430/339. Acesso em 14 de junho de 2020

DE BARROS, Sergio Resende. O Desdobramento dos Direitos Humanos da Família. Revista Escola de Magistratura do Estado de Rondônia. P. 161 - 170. 2001. Disponivel em: https://emeron.tjro.jus.br/images/biblioteca/revistas/emeron/revista-emeron-200614.pdf\#page=49. Acesso em 09 de junho de 2020.

DE CAMPOS, Orlando Narvaes; RODRIGUES, Angelica Cristina; PINTO, Rosa Maria Ferreiro. Vacinação Infantil: Uma Questão de Dever e Não de Autonomia. Anais do Encontro Nacional de Pós Graduação, v. 3, n. 1, p. 423-427, 2019. Disponivel em: https://ojs.unisanta.br/index.php/ENPG/article/view/2169/1666. Acesso em 10 de junho de 2020

DE QUEVEDO, Josemari Poerschke et al. A política de vacinação contra o HPV no Brasil: a comunicação pública oficial e midiática face à emergência de controvérsias. Revista Tecnologia e Sociedade, v. 12, n. 24, p. 1-26, 2016. Disponivel em: https://www.redalyc.org/pdf/4966/496654011002.pdf. Acesso em 13 de junho de 2020.

DIAS, Maria Berenice; DE SOUZA, Ivone MC Coelho; DO JUSMULHER. Famílias modernas:(inter) secções do afeto e da lei. Revista Brasileira de Direto de Família. Porto Alegre, v. 2, n. 8, p. 62-69, 2001.

DOS SANTOS, Danielle Maria Espezim; VERONESE, Josiane Rose Petry. A proteção integral e o enfrentamento de vulnerabilidades infanto adolescentes. Revista de Direito. Viçosa. Vol. 10. N 02. 2018. P. 109-157. 2018. Disponivel em https://dialnet.unirioja.es/servlet/articulo?codigo=7085867. Acesso em 28 de maio de 2020.

FÁvero, E.T. MELÃO, M.J.R. \& JORGE, M.R.T (org.). O Serviço Social e a Psicologia no Judiciário: construindo saberes, conquistando direitos. São Paulo: Cortez, 2008

FINCATO, Denise Pires. A pesquisa jurídica sem mistérios: da pesquisa à banca. 2 ed. rev e amp. Porto Alegre: Sapiens, 2014. 
FLORES, Joaquin Herrera Flores. Colonialismo y violência. Bases para uma reflexión poscolonial desde los derechos humanos. Revista Crítica de Ciências Sociais. N ${ }^{\circ} 75$. Outubro. 21-40, 2006.

FRASER, Nancy. A justiça social na globalização: redistribuição, reconhecimento e participação. Revista Crítica de Ciências Sociais, 63. Outubro - 2002, p.7-20.

GERVASONI, Tássia Aparecida. Estado e Direito em trânsito na pós-modernidade. Florianópolis, Santa Catarina: Empório do Direito, 2017.

GLOBEKNER, Osmir. Racionalidade econômica, escolhas trágicas e o custo dos direitos no acesso à saúde. Diké-Revista Jurídica, v. 16, 2017. Disponivel em: http://periodicos.uesc.br/index.php/dike/article/view/1564. Acesso em 13 de junho de 2020.

HUSSAIN, Azhar et al. The anti-vaccination movement: a regression in modern medicine. Cureus, v. 10, n. 7, 2018. Disponivel em: https://www.cureus.com/articles/13250the-anti-vaccination-movement-a-regression-in-modern-medicine. Acesso em 08 de junho de 2020

LIMA, Fernanda da Silva; VERONESE, Josiane Rose Petry. Os direitos da criança e do adolescente: a necessária efetivação dos direitos fundamentais-Volume V. 2012. Disponivel em: https://repositorio.ufsc.br/bitstream/handle/123456789/99635/VD-Direito-daCrianca-18-09-2012.pdf? sequence=1\&isAllowed=y. Acesso em 08 de junho de 2020.

MAUS, Ingeborg. Judiciário como superego da sociedade: o papel da atividade jurisprudencial na "sociedade órfã". Novos estudos CEBRAP, v. 58, 2000. Disponivel em: https://www.researchgate.net/profile/Martonio_Barreto_Lima/publication/309113051_Judicia rio_como_Superego_da_Sociedade_Traducao_do_alemao_por_Martonio_M_B_Lima_e_Paul o_A_de_M_Albuquerque/links/57ffa2bc08aec3e477ea980c/Judiciario-como-Superego-daSociedade-Traducao-do-alemao-por-Martonio-M-B-Lima-e-Paulo-A-de-M-Albuquerque.pdf. Acesso em 13 de junho de 2020.

MATOS, Cristiane Rodrigues Assunção de. Entre a garantia e a restrição de direitos: a judicialização das situações de violência doméstica e familiar contra crianças e adolescentes. 2013.

Disponivel

em:

https://repositorio.unb.br/bitstream/10482/14756/1/2013_CristianeRodriguesAssuncaoMatos. pdf. Acesso em 13 de junho de 2020.

NASSARALLA, Anna Paula Amaral et al. Dimensões e consequências do movimento antivacina na realidade brasileira. Revista educação em Saúde, v. 7, n. 1, 2019. Disponivel em: http://revistas.unievangelica.com.br/index.php/educacaoemsaude/article/view/3813/2651. Acesso em 08 de junho de 2020.

OLMOS, Ana. Publicidade dirigida à criança: violência invisível contra a infância. Constr. psicopedag., São Paulo , v. 19, n. 19, p. 34-46, 2011 . Disponível em <http://pepsic.bvsalud.org/scielo.php?script=sci_arttext\&pid=S141569542011000200003\&ln $\mathrm{g}=$ pt\&nrm=iso $>$. acessos em 11 jun. 2020. 
PAES, Nadinne Sales Callou Esmeraldo. A vacinação obrigatória de crianças e de adolescentes em face da autonomia dos pais no exercício do poder familiar. Meritum, Revista de Direito da Universidade FUMEC, v. 13, n. 2, 2018. Disponivel em: http://www.fumec.br/revistas/meritum/article/view/6450/pdf. Acesso em 10 de junho de 2020.

POTTUMATI, Eduardo Carlos; DE MEIRELLES, Jussara Maria Leal. A judicialização da saúde e seus desafios. Revista Opinião Jurídica (Fortaleza), v. 12, n. 16, p. 130, 2014. Disponivel em: https://periodicos.unichristus.edu.br/opiniaojuridica/article/view/255/144. Acesso em 13 d ejunho de 2020.

ROVER, Tadeu. Pais não podem deixar de vacinar filhos por questões ideológicas, decide TJSP. CONJUR - Consultor Jurídico. https://www.conjur.com.br/2019-ago-12/pais-naopodem-deixar-vacinar-filhos-questoes-ideologicas. Publicado em 12 de agosto de 2019. Acesso em 05 de junho de 2020.

SUCCI, Regina Célia de Menezes. Recusa vacinal-que é preciso saber. Jornal de Pediatria, v. 94, n. 6, p. 574-581, 2018. Disponivel em: https://www.scielo.br/scielo.php?pid=S0021$75572018000600574 \&$ script=sci_arttext\&tlng=pt. Acesso em 08 de junho de 2020

VASCONCELLOS-SILVA, Paulo Roberto; CASTIEL, Luis David; GRIEP, Rosane Härter. A sociedade de risco midiatizada, o movimento antivacinação e o risco do autismo. Ciência \& Saúde Coletiva, v. 20, p. 607-616, 2015. Disponivel em: https://www.scielosp.org/article/csc/2015.v20n2/607-616/. Acesso em 08 de junho de 2020

WAQUIM, Bruna Barbieri; COELHO, Inocêncio Mártires; DE MORAES GODOY, Arnaldo Sampaio. A história constitucional da infância no Brasil à luz do caso do menino Bernardino. Revista Brasileira de Direito, v. 14, n. 1, p. 88-110, 2018. Disponivel em: https://dialnet.unirioja.es/servlet/articulo?codigo=6787001. Acesso em 08 de junho de 2020 . 